Am. J. Trop. Med. Hyg., 32(4), 1983, pp. 741-746

Copyright (c) 1983 by The American Society of Tropical Medicine and Hygiene

\title{
ONCHOCERCOMAS IN GUATEMALA, WITH SPECIAL REFERENCE TO APPEARANCE OF NEW NODULES AND PARASITE CONTENT*
}

\author{
Y. AOKI, $†$ M. SAKAMOTO, $\uparrow$ T. YOSHIMURA, $\ddagger$ I. TADA,$\S$ \\ M. M. RECINOS, "AND H. FIGUEROA M." \\ †Department of Parasitology, Institute for Tropical Medicine, Nagasaki University, Nagasaki, Japan, \\ $\ddagger$ Department of Human Ecology, University of Occupational and Environmental Health, \\ Kitakyushu, Japan, §Department of Parasitic Diseases, Kumamoto University School \\ of Medicine, Kumamoto, Japan, and "Servicio Nacional de Erradicacion \\ de la Malaria, Ministerio de Salud Publica, Guatemala
}

\begin{abstract}
To determine the rate of appearance of new nodules during a specified period, a follow-up study on onchocercomas that had been removed was carried out in San Vicente Pacaya, Guatemala, between June 1976 and April 1977. Incidence rate, or rate of nodules appearing in initially negative subjects, was studied in relation to the degree of endemicity. Rates in a period of 7-8 months in high, medium, and low endemic areas were $0.231,0.083$, and 0.022 , respectively. The rate of nodule appearance in persons nodulectomized, or rate of nodules appearing in subjects who were surgically rendered negative during the first survey, was $45.3 \%, 36.4 \%$, and $4.5 \%$ in those areas. The highest rate of nodule appearance was observed in patients with microfilariae in both the skin and nodules, followed by patients with either microfilariae or nodules. In highly endemic areas, new nodules appeared in $13.2 \%$ of persons without microfilariae or nodules, while in low endemic areas even patients with nodules earlier were less likely to have developed new ones. The performance of the nodulectomy teams (brigadas) was evaluated by confirming the worms in nodules. By gross examination alone, about $6 \%$ of nodules removed by brigadas did not contain worms. Nodules containing worms were examined for microfilariae to clarify their role as a source of microfilariae. Microfilariae were not detected in some of these nodules, especially in small ones. In contrast, microfilariae emerged from $80 \%$ of those larger than $10 \mathrm{~mm}$. Number of worms per nodule, their sex, and the fecundity of female worms were examined by a collagenase technique. The average number of worms per nodule was 0.6 males and 1.2 females. The highest burden in any one nodule was seven worms, four females and three males. Most nodules had one female and either one male worm or none. Intrauterine microfilariae were found in most females from nodules shared with a male, while solitary females were not gravid. Solitary females were likely to be found in small nodules and large nodules were more likely to include both sexes.
\end{abstract}

Since 1933 a nationwide nodulectomy campaign has been conducted in Guatemala as a control measure, but not as radical treatment, of onchocerciasis; ${ }^{1}$ all known endemic areas have been visited once or twice a year by paramedical nodulectomy teams or "brigadas." Although there is evidence of a reduced prevalence of onchocercal blindness, ${ }^{2}$ overall morbidity appears to have remained unaffected. ${ }^{3}$ Romero and Wise questioned the effectiveness of mass nodulectomy as a means

Accepted 16 August 1982

* This study was supported by the Ministry of Public Health, Guatemala, and Japan International Cooperation Agency, Japan (ORCOP series, No. 53). of disease management, and stressed the need for a critical evaluation. ${ }^{4}$ Fuglsang and Anderson found that removal of head nodules was partially effective in reducing the microfilarial concentration in the cornea, but not in the skin, and was of some benefit to lesions of the anterior segment of the eyes. ${ }^{5}$ They noted, however, that removal of head nodules is far from sufficient as a curative measure in ocular onchocerciasis. Recently, Kale also reported that nodulectomy has no influence in microfilarial density. ${ }^{6}$ The general assumption that nodules, rather than worms free in the skin, are a significant source of microfilariae has not been examined thoroughly in Guatemala.

In this investigation, we examined two major unanswered questions relevant to the value of nodulectomy as a control measure: the role of the 
nodule as a source of microfilariae, and appearance of new nodules in a previously treated population.

\section{MATERIALS AND METHODS}

\section{Survey}

Since 1976 a research and control program against onchocerciasis has been carried out in and around San Vicente Pacaya (SVP), Guatemala. In these areas, we were able to observe the rate of nodule appearance in a given period and to examine parasite contents of nodules during an epidemiological survey conducted between 1976 and 1980. In the initial survey conducted in 1976, almost half of the total population in SVP were interviewed on their history of nodulectomy, to ascertain the extent of work done by brigadas before our survey. Residents were then palpated for nodules, skin snipped, given an anterior chamber examination by slit lamp, and all detected nodules were removed. The morbidity of disease, population and topography of SVP have been published in our previous paper. ${ }^{7}$ Twelve villages and plantations surveyed between June and September in 1976 were selected as the study area for appearance of new nodules. The total population of areas selected was about 2,000. A follow-up survey was conducted between January and April in 1977, 7-8 months after the first survey. At the second survey the inhabitants were re-examined for nodules and nodulectomy was done where needed, but skin snips were not taken. In our study, all nodules diagnosed and removed by brigadas were regarded as of onchocercal origin. To determine the rate of appearance of new nodules, only persons examined in both surveys were used. The rate of new nodules appearing in the initially negative subjects was expressed as an incidence rate, based on a period of 7-8 months; this was defined as the number of subjects with new nodules in the second survey divided by the total number of initially negative subjects in the first survey. The rate of new nodules appearing in persons surgically rendered negative may be regarded as "the rate of nodule appearance in the nodulectomized." This was calculated as the number of subjects with new nodules in the second survey divided by the total number of subjects surgically rendered negative among nodule positives in the first survey. The study areas arbitrarily classified into three zones according to skin microfilaria positive rate
(MF) at the time of the first survey in 1976. MF, nodule positive rate (NPR) and microfilaria positive rate in anterior chamber of the eyes (MFAC) in each of three zones were as follows: High endemic areas, MF, 62.3-80.3\%, NPR, 3.46-73.3\%, MFAC, 6.7-27.9\%; Medium endemic areas, MF, 35.6-38.7\%, NPR, 17.8-34.4\%, 3.8-10.2\%; Low endemic areas, Mf, 7.6-18.2\%, NPR, 9.7-15.1\%, MFAC, $0-1.4 \%$.

\section{Examination of nodules}

A total of 888 nodules were examined; 591 nodules collected in 1977, 179 of which were new nodules obtained at follow-up survey described previously, and 297 nodules collected in 1979 1980. The nodules were measured using callipers after removal of their loose connective tissue, and the size of each was expressed as the arithmetic mean of their three dimensions. To evaluate the diagnostic certainty in palpation of nodule by brigadas, nodules collected in 1977 were cut into several pieces using surgical blade and examined for worms under dissecting microscope. At least 555 (94\%) of 591 nodules examined were confirmed to contain the worm, without the use of histological techniques. The nodules containing worms were minced and soaked in saline for $30 \mathrm{~min}$ to allow microfilariae to emerge. In 1979 and 1980, whole nodules were kept on ice for 2-3 days, followed by collagenase digestion ${ }^{8}$ to determine the number of worm per nodule, their sex, and the fecundity of female worms. Of 297 nodules examined, 276 (93\%) contained at least one worm. Sixteen nodules contained calcified or fragmented worms and were excluded from calculation. Recovered male worms were intact, but perhaps other broken ones escaped detection. Most female worms recovered were severed in at least several points.

\section{RESULTS}

\section{Survey data}

Pre-1976 nodulectomy histories (Table 1) indicated that the proportion of those receiving at least one nodulectomy increased with age, to a maximum of almost $75 \%$ in the over 20 age group. The highest proportion of nodulectomized individuals was observed in the area of maximum endemicity.

Of the 1,631 subjects screened in 1976,874 (53.5\%) were re-examined in 1977 (Table 2). The nodules were detected in 235 (26.9\%) of 874 sub- 
TABLE 1

Patient histories of onchocercal nodulectomy performed by brigadas prior to 1976 in San Vicente Pacaya, Guatemala, summarized by age and degree of endemicity

\begin{tabular}{|c|c|c|c|c|}
\hline \multirow{3}{*}{$\begin{array}{l}\text { Degree of } \\
\text { endemicity* }\end{array}$} & \multicolumn{4}{|c|}{ Proportion of persons surveyed reporting at least one nodulectomy } \\
\hline & \multicolumn{3}{|c|}{ Age (yrs) } & \multirow[b]{2}{*}{ Total } \\
\hline & $0-9$ & $10-19$ & $\geqslant 20$ & \\
\hline High & $29 / 69(42.0) \dagger$ & $34 / 48 \quad(70.8)$ & $59 / 79 \quad(74.7)$ & $122 / 196(62.2)$ \\
\hline Medium & $10 / 209(4.8)$ & $48 / 157(30.6)$ & $139 / 308(45.1)$ & $197 / 674(29.2)$ \\
\hline Low & $0 / 129$ & $6 / 86 \quad(7.0)$ & $39 / 166(23.5)$ & $45 / 381(11.8)$ \\
\hline
\end{tabular}

See Materials and Methods.

† No. reporting nodulectomy/no. questioned (\% reporting).

jects in the first survey and $138(15.8 \%)$ in the second survey. The average number of nodules per person was reduced from 1.77 in 1976 to 1.38 in 1977 . Of 639 persons initially without nodules, $46(7.2 \%)$ showed new nodules. Again, the highest incidence rate was observed in the inhabitants of highly endemic zones. Among 226 persons surgically rendered nodule-negative in 1976, the rate of appearance of new nodules was about fivefold (36.7\%) that seen in the initially negative group.

When 1976 examinees were classified as positive or negative by skin snip and nodules (Table 3 ), the highest rate of nodule appearance was observed in the patients with both microfilariae in the skin and nodules, in high and medium endemic areas. In the low endemic areas, even patients with onchocercal signs were less likely to show new nodules. In the highly endemic areas, new nodules appeared among $13.2 \%$ of persons initially without microfilariae and nodules.

\section{Examination of nodules}

The sizes of nodules collected from villages surveyed between April and July in 1977 ranged from
3.3-18.0 mm with mean of $8.2 \pm 2.7 \mathrm{~mm}(\mathrm{n}=$ 388). Microfilariae were not detected in some nodules, even those with worms; detection rate of microfilariae increased with nodule size (Table 4). Microfilariae were not detected in nodules smaller than $3.9 \mathrm{~mm}$. They emerged from one-fourth of those $4.0-5.9 \mathrm{~mm}$ and from $81 \%$ of those greater than $10 \mathrm{~mm}$. The new nodules obtained at the follow-up study between January and April in 1977 varied from $3.5 \mathrm{~mm}-19.7 \mathrm{~mm}$ with mean of $7.4 \pm$ $2.8 \mathrm{~mm}(\mathrm{n}=136)$ in size. Microfilariae emerged from $30 \%$ of those nodules smaller than $5.9 \mathrm{~mm}$, from $59 \%$ of those between 6.0 and $9.9 \mathrm{~mm}$ and from $89 \%$ of those greater than $10 \mathrm{~mm}$.

Of 484 total identifiable worms recovered from 260 onchocercomas, $66.7 \%$ were female and $33.3 \%$ were male. Measurable males averaged $2.5 \pm 0.6$ $\mathrm{cm}$ in length $(1.4-4.5 \mathrm{~cm})$ and females averaged $32.9 \pm 11.2 \mathrm{~cm}(8.9-69.7 \mathrm{~cm})$. When nodules were categorized by number and sex of enclosed worms (Table 5), it was apparent that the majority of nodules $(81.2 \%)$ had only one female worm; the great majority likewise had either one or no male worms and higher numbers were progressively more unlikely. The average number of worms per

TABLE 2

Comparison of results of two onchocercal nodule surveys in San Vicente Pacaya, Guatemala, by presence or absence of nodules and by degree of endemicity

\begin{tabular}{|c|c|c|c|c|c|c|c|c|c|}
\hline \multirow[b]{2}{*}{$\begin{array}{l}\text { Degree of } \\
\text { endemicity* }\end{array}$} & \multirow[b]{2}{*}{$\begin{array}{l}\text { Nodules (1976) } \\
\text { Nodules (1977) }\end{array}$} & \multicolumn{3}{|c|}{ No treatment } & \multicolumn{2}{|c|}{ Nodulectomy } & \multirow[b]{2}{*}{$\begin{array}{l}\text { Total no. } \\
\text { surveyed }\end{array}$} & \multirow[b]{2}{*}{$\begin{array}{c}\text { Incidence } \\
\text { rate } \dagger\end{array}$} & \multirow{2}{*}{$\begin{array}{c}\text { Rate } \\
\text { of new } \\
\text { nodule } \\
\text { appearance } \\
\text { in nodulec- } \\
\text { tomized } \\
\text { persons } \ddagger\end{array}$} \\
\hline & & $\begin{array}{l}\text { Neg. } \\
\downarrow \\
\text { Neg. }\end{array}$ & $\begin{array}{l}\text { Neg. } \\
\downarrow \\
\text { Pos. }\end{array}$ & $\begin{array}{l}\text { Pos. } \\
\downarrow \\
\text { Pos. }\end{array}$ & $\begin{array}{l}\text { Pos. } \\
\text { Neg. }\end{array}$ & $\begin{array}{l}\text { Pos. } \\
\downarrow \\
\text { Pos. }\end{array}$ & & & \\
\hline \multirow{3}{*}{\multicolumn{2}{|c|}{$\begin{array}{l}\text { High } \\
\text { Medium } \\
\text { Low }\end{array}$}} & $50 \S$ & 15 & 3 & 47 & 39 & 154 & 0.231 & 0.453 \\
\hline & & 278 & 25 & 5 & 75 & 43 & 426 & 0.083 & 0.364 \\
\hline & & 265 & 6 & 1 & 21 & 1 & 294 & 0.022 & 0.045 \\
\hline \multicolumn{2}{|c|}{ Total no. surveyed } & 593 & 46 & 9 & 143 & 83 & 874 & 0.072 & 0.367 \\
\hline
\end{tabular}


TABLE 3

Comparison of results of two onchocercal nodule surveys in San Vicente Pacaya, Guatemala, by presence or absence of microfilariae in skin and nodules, and by degree of endemicity

\begin{tabular}{|c|c|c|c|c|}
\hline $\begin{array}{l}\text { Degree of } \\
\text { endemicity* }\end{array}$ & $\begin{array}{c}\text { Microfil } \\
\text { in skin } \\
\text { nodules it }\end{array}$ & $\begin{array}{l}\text { lariae } \\
\text { and } \\
\text { n } 1976\end{array}$ & $\begin{array}{l}\text { No. of } \\
\text { cases }\end{array}$ & $\begin{array}{l}\text { No. positive } \\
\text { for nodules } \\
\text { in } 1977(\%)\end{array}$ \\
\hline Low & $\begin{array}{l}\text { MF }+(-) \\
\text { Mf (-) } \\
\text { Mf (+) } \\
\text { Mf (+) }\end{array}$ & $\begin{array}{l}\mathbf{N} \ddagger(-) \\
\mathbf{N}_{(+)} \\
\mathbf{N}_{(-)} \\
\mathbf{N}_{(+)}\end{array}$ & $\begin{array}{r}252 \\
13 \\
19 \\
9\end{array}$ & $\begin{array}{l}5(2.0) \\
1(7.7) \\
1(5.3) \\
0\end{array}$ \\
\hline Medium & $\begin{array}{l}\text { Mf (-) } \\
\text { Mf (-) } \\
\text { Mf (+) } \\
\text { Mf (+) }\end{array}$ & $\begin{array}{l}\mathbf{N}_{(-)} \\
\mathbf{N}_{(+)} \\
\mathbf{N}_{(-)} \\
\mathbf{N}_{(+)}\end{array}$ & $\begin{array}{r}242 \\
32 \\
61 \\
86\end{array}$ & $\begin{aligned} 12 & (5.0) \\
5 & (15.6) \\
13 & (21.3) \\
38 & (44.2)\end{aligned}$ \\
\hline High & $\begin{array}{l}\text { Mf }(-) \\
\text { Mf }(-) \\
\text { Mf (+) } \\
\text { Mf }(+)\end{array}$ & $\begin{array}{l}\mathbf{N}_{(-)} \\
\mathbf{N}_{(+)} \\
\mathbf{N}_{(-)} \\
\mathbf{N}_{(+)}\end{array}$ & $\begin{array}{l}38 \\
11 \\
27 \\
75\end{array}$ & $\begin{array}{r}5(13.2) \\
4(36.4) \\
10(37.0) \\
35(46.7)\end{array}$ \\
\hline
\end{tabular}

nodule was 0.6 males and 1.2 females. The highest burden in any one nodule was seven worms, four females and three males. Almost half of 260 nodules contained at least one worm of either sex. With a single exception, all unisexual nodules contained a female worm. Only one unisexual nodule containing a male worm was found.

Examination of sex distribution with respect to nodule size showed that solitary females were likely to be found in small nodules and that larger nodules were more likely to include both sexes. Nineteen percent of all nodules smaller than 5.9 $\mathrm{mm}$ contained worms of both sexes, while $62.6 \%$ of those exceeding $8 \mathrm{~mm}$ represented both sexes. In a sample of 100 female worms, the male's pres-

TABLE 4

Relationship between nodule size and presence of microfilariae*

\begin{tabular}{ccc}
\hline $\begin{array}{c}\text { Size of nodule } \\
(\mathrm{mm})\end{array}$ & $\begin{array}{c}\text { No. nodules } \\
\text { examined } \\
\text { (frequency } \\
\text { distribution: } \%)\end{array}$ & $\begin{array}{c}\text { No. nodules } \\
\text { positive } \\
\text { for microfilariae } \\
(\%)\end{array}$ \\
\hline$<3.9$ & $4(1.0)$ & 0 \\
$4.0-5.9$ & $79(20.4)$ & $20(25.3)$ \\
$6.0-7.9$ & $125(32.2)$ & $75(60.0)$ \\
$8.0-9.9$ & $90(23.2)$ & $66(73.3)$ \\
$10.0-11.9$ & $44(11.3)$ & $35(79.5)$ \\
$12.0<$ & $46(11.9)$ & $38(82.6)$ \\
Total & 388 & $234(60.3)$ \\
\hline
\end{tabular}

* Of 412 nodules examined, 24 contained no worms and were exclude from calculation.
TABLE 5

Two-way frequency distribution of nodules with respect to the number and sex of enclosed $O$. volvulus

\begin{tabular}{|c|c|c|c|c|c|c|c|}
\hline \multirow{2}{*}{$\begin{array}{l}\text { No. } \\
\text { female } \\
\text { worms/ } \\
\text { nodule }\end{array}$} & \multicolumn{6}{|c|}{ No. male worms/nodule } & \multirow{2}{*}{$\begin{array}{c}\text { Total } \\
\text { nodules }\end{array}$} \\
\hline & 0 & 1 & 2 & 3 & 4 & 5 & \\
\hline 0 & 0 & 1 & 0 & 0 & 0 & 0 & 1 \\
\hline 1 & 118 & 80 & 10 & 2 & 0 & 1 & 211 \\
\hline 2 & 12 & 16 & 6 & 2 & 0 & 0 & 36 \\
\hline 3 & 2 & 3 & 3 & 0 & 0 & 0 & 8 \\
\hline 4 & 0 & 3 & 0 & 1 & 0 & 0 & 4 \\
\hline $\begin{array}{c}\text { Total } \\
\text { nodules }\end{array}$ & 132 & 103 & 19 & 5 & 0 & 1 & 260 \\
\hline
\end{tabular}

ence was associated with the appearance of intrauterine microfilariae. Intrauterine microfilariae were found in most $(85.4 \%)$ of 41 females from nodules shared with males, whereas all of 59 solitary females were not gravid.

\section{DISCUSSION}

So far, the nodule rate has been used as the index of endemicity of onchocerciasis in Guatemala. ${ }^{9}$ In SVP, Guatemala, we have previously showed that about $16 \%$ of those infected were nodule-positive and were negative for cutaneous or ocular microfilariae. Therefore, nodule palpation is a valuable diagnostic procedure, especially among children in Guatemala. Detection and removal of nodules in Guatemala is performed by experienced paramedical personnel called brigadas, during their annual or semiannual visits. The brigadas' work before our first survey is presented in this study. The percentage of nodulectomized population in our study area was especially high $(62 \%)$, in highly endemic areas. It appears that new nodules can be formed in a period of 6 months.

The rate of appearance of new nodules in Guatemala was first established by follow-up study. Both the incidence rate and rate of nodule appearance in the nodulectomized were correlated with the degree of endemicity. The degree of endemicity in SVP was reported to be altitude-dependent, and the highest microfilaria rate was found in villages situated between 600 and $900 \mathrm{~m}$ above sea level. ${ }^{7}$ In highly endemic areas, the incidence rate was 0.231 , and $45.3 \%$ of those nodulectomized again presented nodules within 7-8 months. The highest rate of nodule appearance was observed in the patients with microfilariae in the skin and nodules, followed by patients with 
either microfilariae or nodules, in high and medium endemic areas. In highly endemic areas, new nodules appeared among $13.2 \%$ of persons without microfilariae or nodules. In low endemic areas, even the patients with either microfilariae or nodules were less likely to show the new nodules. The higher rate of nodule appearance probably represents more frequent exposure to vector flies in highly endemic areas.

The rate of nodule appearance might be affected by the erroneous diagnosis by brigadas. To evaluate the performance of brigadas in the present study, the nodules removed by brigadas were examined for worms. Thirty-six (6.1\%) of 591 nodules examined did not harbor Onchocerca volvulus. Even some of the nodules without apparent worms might have also been onchocercal, as no histological technique was applied. The frequency of misdiagnosis (6\%) can be regarded as inevitable, because it is sometimes difficult to distinguish other tumors from onchocercomas by palpation, especially when they are small.

To date, little is known about the stimuli which provoke nodule formation. They may develop in response to dead worms, ${ }^{10}$ or they may represent a unique response to mature adults. ${ }^{11}$ According to Schulz-Key, O. flexuosa nodules are induced by the immature stage of the parasite. ${ }^{12}$ Recently Collins et al. ${ }^{13}$ observed that the nodules form only around female worms. Nodules detected in our resurvey presumably represented the growth of nodules which had been too small to be palpated, the encapsulation of worms free in tissue at the time of the first survey, or perhaps the encapsulation of worms transmitted by flies since the first nodulectomy.

Our nodules differ from those studied in Africa ${ }^{14}$ in a number of respects. Guatemalan nodules were much smaller, contained about half as many worms, and these worms were rarely calcified (less than $2 \%$ ). About half the African nodules measured less than $10 \mathrm{~mm}$ and one third were less than $8 \mathrm{~mm}$. Our corresponding figures were $76.8 \%$ and $53.6 \%$. African nodules were more likely to contain both sexes $(82.7 \%)$ than Guatemalan (48.8\%). These differences may reflect the active nodulectomy campaign in Guatemala. Even though examined when fresh, a high proportion of Guatemalan nodules (40\%) were without detectable microfilariae. Small nodules were less likely to contain microfilariae than large ones. About half our nodules contained only solitary, nongravid females but a high proportion of fe- males sharing nodules with males $(85.4 \%)$ were gravid. We also noted that the proportion of nodules containing both sexes increases with nodule size. Similar observations have been reported on the Australian cattle onchocercid, O. gibsoni. ${ }^{15}$ Contrary to our experience, gravid females in nodules without males have been observed in human $^{13,14}$ and animal ${ }^{15}$ onchocerciasis. Perhaps male worms move among nodules, ${ }^{12}$ worms are overlooked, ${ }^{15}$ or mating occurs before or early during the formation of nodules. ${ }^{13}$

It is generally believed that microfilariae leave the nodule ${ }^{16}$ and spread into the dermis and eyes. The rationale behind mass nodulectomy campaigns has been that repeated nodulectomy would reduce the skin density of microfilariae. In one small village with a population of about 160 and microfilaria rate of $85 \%$, we removed all detectable nodules from 10 patients and then examined quantitatively the change of concentration of $\mathrm{mi}$ crofilariae in the skin every 2 months for one year. Each of the subjects had at least one nodule containing both sexes of worm. Six months after the nodulectomy, six patients developed new nodules which were again removed. The change of microfilarial density seemed quite variable and in none of the patients was a significant tendency to decrease shown within the period of observation (unpublished data). Fuglsang and Anderson, ${ }^{5}$ and Kale, ${ }^{6}$ report a similar experience after removal of African nodules. Effectiveness of nodulectomy is perhaps masked by several factors, such as the activity of deep, unpalpable nodules, ${ }^{17}$ adult worms lying free in the subcutis, ${ }^{18}$ a long microfilarial life span, ${ }^{19}$ or uneven distribution of dermal microfilariae, even in adjacent locations. ${ }^{20}$ We failed to demonstrate a direct efficacy of nodulectomy on microfilarial density in the skin, but large nodules can be stressed as the significant source of microfilariae, which are the pathogenic stage in onchocerciasis.

\section{ACKNOWLEDGMENTS}

The authors are indebted to Drs. J. J. Castillo O. and H. A. Godoy B. of Servicio Nacional de Erradicacion de la Malaria, Guatemala and their colleagues for their kind cooperation. The authors wish to express special appreciation to Dr. A. L. Vincent of the College of Medicine, University of South Florida, for his helpful criticism and suggestions in the preparation of the manuscript. Appreciation is also expressed to Dr. Y. Hashiguchi, 
Dr. T. Oda, and Mr. J. O. Ochoa A., for their encouragement in carrying out the work.

\section{REFERENCES}

1. Bernhard, J. A., 1965. Twenty five years of onchocerciasis control in Guatemala. WHO/ONCHO/INF/10.65.

2. Diaz, F. A., 1957. Notes and observations on onchocerciasis in Guatemala. Bull. W.H.O., 16: 676-681.

3. Figueroa M., H., and Guillioli, C. G., 1971. Observations on the prevalence of Robles' disease (onchocerciasis) in Guatemalan foci, with special reference to denodulization. WHO/ONCHO/ 71.86 .

4. Romero, A., and Wise, R., 1978. Nodulectomy for onchocerciasis? N. Engl. J. Med., 299: 779.

5. Fuglsang, H., and Anderson, J., 1978. Further observations on the relationship between ocular onchocerciasis and the head nodule, and on the possible benefit of nodulectomy. Br.J. Ophthalmol., 62: 445-449.

6. Kale, O. O., 1982. Controlled studies on the effect of nodulectomy on the concentration of microfilariae in the skin of patients exposed to continuing transmission of Onchocerca volvulus in the rainforest zone of Western Nigeria. Tropenmed. Parasitol., 33: 40-42.

7. Tada, I., Aoki, Y., Rimola, C. E., Ikeda, T., Matsuo, K., Ochoa, J. O. A., Recinos, M. M., Sato, S., Godoy, H. A. B., Orellana, J. J. C., and Takahashi, H., 1979. Onchocerciasis in San Vicente Pacaya, Guatemala. Am. J. Trop. Med. Hyg., 28: 67-71.

8. Schulz-Key, H., Albiez, E. J., and Büttner, D. W., 1977. Isolation of living adult Onchocerca vol vulus from nodules. Tropenmed. Parasitol., 28: 428-430.

9. Estrada S., C., Bernhard, J. A., Figueroa, L. N., and Garcia M., A., 1963. Epidemiologia, Enfermedad de Robles. Editorial Universitaria, Guatemala, 84-93.
10. Israel, M. S., 1959. The nodule in onchocerciasis. Trans. R. Soc. Trop. Med. Hyg., 53: 142-147.

11. Oomen, A. P., 1967. Onchocerciasis in the Kaffa province of Ethiopia. Trop. Geogr. Med., 19: 231-246.

12. Schulz-Key, H., 1975. Untersuchungen über die filarien der cerviden in Süddeutschland. 1. Knotenbildung, geschlechterfindung und mikrofilarienausschüttung bei Onchocerca flexuosa (Wedl, 1856) im rothirsch (Cervus elaphus). Tropenmed. Parasitol., 26: 60-69.

13. Collins, R. C., Lujan, R. L., Figueroa M., H., and Campbell, C. C., 1982. Early formation of the nodule in Guatemalan onchocerciasis. Am. J. Trop. Med. Hyg., 31: 267-269.

14. Schulz-Key, H., and Albiez, E. J., 1977. Worm burden of Onchocerca volvulus in a hyperendemic village of the rain-forest in West Africa. Tropenmed. Parasitol., 28: 431-438.

15. Beveridge, I., Kummerow, E. L., and Wilkinson, P., 1980. Observation on Onchocerca gibsoni and nodule development in naturally-infected cattle in Australia. Tropenmed. Parasitol., 31: 75-81.

16. Figueroa M., H., 1974. Robles disease-How do the microfilariae leave the nodule? Proc. 3rd Int. Congr. Parasit., Munich (1974), 594-595.

17. Duke, B. O. L., 1970. Onchocerciasis; deep worm bundles close to hip joint. Trans. R. Soc. Trop. Med. Hyg., 64: 791-792.

18. Nnochiri, E., 1964. Observations on onchocercal lesions seen in autopsy specimens in Western $\mathrm{Ni}$ geria. Ann. Trop. Med. Parasitol., 58: 89-93.

19. Duke, B. O. L., 1968. The effects of drugs on Onchocerca volvulus. 1. Methods of assessment, population dynamics of the parasite and the effects of diethylcarbamazine. Bull. W.H.O., 39: 137-146.

20. Zea, G. F., Hashiguchi, Y., Kawabata, M., Tada, I., Yoshimura, T., Flores, O. C., and Recinos, M. M., 1980. Guatemalan onchocerciasis: Skin snipping methods and microfilarial densities in a given minute area of the skin. Jap. J. Trop. Med. Hyg., 8: 23-32. 